\title{
EPISTEMOLOGIA GENÉTICA, ALFABETIZAÇÃO \\ E LETRAMENTO
}

Maria Irene Miranda*

\begin{abstract}
RESUMO
Este texto pretende suscitar reflexões sobre o processo de alfabetização e letramento. Os fundamentos epistemológicos foram pautados na perspectiva psicogenética de Jean Piaget, cujos princípios remetem ao sujeito cognoscente que constrói seus conhecimentos modificando suas estruturas mentais a partir das experiências no meio. Sendo assim, o professor alfabetizador, com suas propostas de ensino, tem um papel fundamental não apenas na aprendizagem do aluno, como também na construção de sua cidadania.
\end{abstract}

Palavras-chave: Epistemologia. Alfabetização. Letramento

\begin{abstract}
This text intends to raise reflections on the literacy and lettering process. Epistemologyc foundations have been ruled on the psychogenetic perspective of Jean Piaget, whose principles remit to the acquaintanced citizen that constitutes his knowledge modifying his mental stuctures from the experiences in the circle. Thus, the teachers with his proposals of education, has a fundamental role not only in the student's learning process but also in the construction of his citizenship.
\end{abstract}

Keywords: Epistemologyc. Literacy. Lettering

* Doutora em Educação pela PUC-SP e professora da Faculdade de Educação da Universidade Federal de Uberlândia. E-mail: mirene@ufu.br 


\section{Introdução}

A experiência acadêmica e a literatura sobre o assunto revelam que o processo de alfabetização representa um desafio para os educadores, tanto em relação aos fundamentos teóricos, quanto em relação aos encaminhamentos metodológicos. Isto ocorre pela complexidade do ato de alfabetizar, compreendido somente mediante a oportunidade de realizá-lo. Para alfabetizar, faz-se necessário conhecimentos específicos sobre a linguagem e sobre os processos pelos quais os sujeitos pensam e compreendem a língua, a partir de uma determinada realidade sócio-cultural. Desprovido desses suportes, o alfabetizador pode encontrar grandes dificuldades no desempenho de sua função. A simples aplicação de cartilhas, de livros didáticos ou de métodos pré-definidos não garante a aprendizagem dos alunos. É o caso dos chamados métodos sintéticos (alfabético, fônico e silábico) que centram o ensino nas partes que compõem as palavras (letras, sons e sílabas), privilegiando o processo de codificação e decodificação, assim como a redundância sem sentido de palavras e frases descontextualizadas. Nessa perspectiva, a aprendizagem é considerada como resultado do acúmulo de informações e não como reorganização e reestruturação dos conhecimentos disponíveis. Da mesma forma, os interesses e a realidade cognitiva, emocional e social dos alunos são desconsiderados, como se eles não tivessem noções e hipóteses acerca do funcionamento da língua.

Superando essa tendência mais tradicional, atualmente o processo de ensino e aprendizagem da alfabetização tem uma visão mais ampla do alfabetizando e do significado de ler e escrever. Essa realidade implica em uma nova postura do alfabetizador: torna-se inviável a utilização de métodos que massificam os alunos, já que suas experiências nos diversos contextos letrados são diferentes e, portanto, possibilitam a aprendizagem de forma distinta. Cada um aprende segundo seu nível de desenvolvimento, suas experiências e suas habilidades, logo, todos podem aprender. Por assim ser, o alfabetizador, precisa redimensionar suas

Educ. e Filos., Uberlândia, v. 22, n. 44, p. 141-158, jul./dez. 2008. 
concepções de ensino e aprendizagem de forma a contemplar as diferentes interfaces desses processos.

\section{O Processo de Alfabetização e Letramento}

O conceito de alfabetização tem uma variação histórica, significando desde o domínio da grafia do nome próprio, passando pela leitura e escrita de palavras e frases descontextualizadas e, atualmente, assumindo um sentido mais abrangente, que envolve a leitura (interpretação) e a escrita (produção) em suas diferentes formas e usos. Em outras palavras, para efetivar esse significado, o domínio da alfabetização está vinculado não apenas ao processo de codificação e decodificação, mas também de interpretação, compreensão e produção escrita. Nessa perspectiva, estar alfabetizado corresponde a estar inserido de forma interativa em um contexto letrado. Não basta, portanto, dominar o sistema de funcionamento do código linguístico, é necessário ter competência para ir além, já que o contrário caracteriza o analfabetismo funcional, isto é, a falta de capacidade de utilizar a linguagem, principalmente oral e escrita, em circunstâncias cotidianas.

No Brasil, infelizmente, esta é uma realidade comum. Em 2000, o Jornal "O Popular" noticiou que o índice de analfabetos funcionais brasileiros era preocupante, uma vez que de acordo com pesquisas realizadas em diferentes países latino-americanos, o Brasil obteve o pior resultado nos exercícios de compreensão: os brasileiros demonstraram pouco entendimento do que leram e, ainda, não revelaram competências para assimilar e desenvolver habilidades práticas a partir dos conhecimentos escolares. Conseqüentemente, ficam diminuídas as capacidades de trabalho, de exercer os direitos de cidadania e desenvolver a consciência crítica. Em 2003, a Revista Época informou que o fracasso dos brasileiros no domínio da leitura e da escrita começa a ser delineado no ensino fundamental, pois ao terminarem a primeira série, $96 \%$ (noventa e seis por cento) dos alunos são analfabetos. E ainda, dos que chegam a quarta série, $59 \%$ (cinqüenta e nove por cento) são incapazes de escrever um bilhete simples ${ }^{1}$. Em 2006, um 
documentário exibido em um programa de televisão revelou que mesmo estudantes e/ou profissionais que dispunham de um bom nível de escolaridade nem sempre eram bem sucedidos no mercado de trabalho, que oferece vagas que não são preenchidas por falta de pessoas com formação adequada.

A partir desses dados pode-se inferir que o descompasso entre a escola e a formação para interação e atuação no mundo é um problema recorrente. $\mathrm{O}$ enfrentamento dessa realidade deve consistir na busca de aproximação coerente da prática pedagógica com as necessidades dos alunos e não na identificação dos supostos "culpados pelo fracasso".

Para a pesquisadora Vera Maria Masagão Ribeiro (In: O Popular, 2000), o grande desafio das escolas brasileiras é oferecer uma educação de qualidade que torne a pessoa capaz de assimilar e desenvolver habilidades práticas a partir do que aprende na sala de aula. Para tanto, a visão reducionista de aprendizagem da leitura e da escrita deve ser abolida em favor da valorização dos contextos sócio-culturais nos quais as crianças estão inseridas. Por outro lado, elas devem permanecer na escola, pois o tempo de escolaridade é fundamental, somente a continuidade na formação pode viabilizar o "aprender a aprender".

A capacidade de interagir com o mundo extrapolando o que é aprendido na escola está relacionada a um conceito mais amplo e recente de alfabetização. De acordo com esse princípio, ao ser alfabetizado o sujeito deve ser também letrado, ou seja, ser preparado para utilizar dos conhecimentos para resolver as diversas demandas da vida social, cultural e política, exercendo os deveres e direitos de cidadania, embasado na consciência crítica da realidade. Isto posto, pode-se afirmar que a atual tendência de alfabetização tem um sentido político explícito, vinculando educação e cidadania. Se antes alfabetizar era considerada uma

1 Estes dados são revelados por meio de pesquisa da Fundação Carlos Chagas, realizada a pedido do Instituto Ayrton Senna, com 13 mil crianças em 47 municípios brasileiros.

Educ. e Filos., Uberlândia, v. 22, n. 44, p. 141-158, jul./dez. 2008. 
atividade neutra politicamente, na atualidade, na perspectiva do letramento, ela assume uma relação com as questões sociais mais amplas.

Na década de 60, as idéias de Paulo Freire já contemplavam essa relação. No contexto de sua pedagogia ativa e dialógica, alfabetização sempre correspondeu a algo além do domínio de técnicas de leitura e escrita, nada de "memorização mecânica das sentenças, das palavras, das sílabas, desvinculadas de um universo existencial" (Freire, 1979, p.72). Estar alfabetizado significa "entender o que se lê e escrever o que se entende" (Idem). Em sendo assim, é por meio do conhecimento que o sujeito supera a consciência ingênua e atinge a consciência crítica da realidade, que favorece a compreensão genuína da causalidade dos fenômenos sociais. Freire pensava a educação enquanto ato político, portanto extrapolando a sala de aula e projetando-se para os problemas enfrentados pela humanidade. Em suas palavras,

[...] no processo de aprendizagem, só aprende verdadeiramente aquele que se apropria do aprendido, transformando-o em apreendido, com o que pode, por isso mesmo, reinventá-lo; aquele que é capaz de aplicar o aprendido-apreendido a situações existenciais concretas. (Freire, 1977, p.27-28)

Na perspectiva progressista e transformadora de educação, a alfabetização nunca foi restrita aos mecanismos de codificação e decodificação, correspondendo, sim, ao processo de apropriação do conhecimento, por meio do qual o sujeito pode superar a alienação e construir sua condição de existência na relação dialética com o meio: constituindo e constituindo-se.

Dessa forma, não cabe sobreposição de conceitos entre letramento e alfabetização, já que essa é desencadeada pelo acesso a cultura letrada, que, por sua vez, é legitimada, também, pelo domínio da alfabetização. Historicamente, desde que foram inventados os sistemas de escrita, fez-se necessário socializar suas regras de funcionamento para que as pessoas pudessem utilizálos adequadamente e, assim, interagir no contexto letrado. 
Insistir na sobreposição de conceitos significa negar a relação entre esses processos e, ainda, implica na possibilidade de transformar o letramento em mais um modismo educacional: o entendimento não ultrapassa os limites do discurso, portanto, não se configura enquanto prática pedagógica.

Diante dessa tendência, o cotidiano do alfabetizador tem sido palco de grandes embates teóricos e práticos acerca dos métodos e processos de alfabetização, contemplando não apenas os aspectos metodológicos, mas também, psicológicos, filosóficos, sociológicos e linguísticos. Por se tratar de um conhecimento interdisciplinar, a alfabetização precisa estar respaldada em princípios que sustente sua complexidade.

Nessa perspectiva, a epistemologia genética de Jean Piaget pode oferecer importantes contribuições, pois mesmo não sendo um alfabetizador, ao aborda os processos de aquisição de conhecimentos, sua teoria tem implicações, repercussões e aplicações pedagógicas, apesar das dificuldades e equívocos acerca dessa transposição. É importante esclarecer que o referencial teórico piagetiano é um caminho importante para a compreensão do conhecimento, porém não é o único, já que seus pressupostos são explicativos e não normativos, estão em (re)construção constante, são, portanto, antidogmáticos, como ele mesmo afirmou: "Se algum dia se falasse do 'sistema de Piaget', essa seria a prova de meu fracasso" (citado por Ferreiro, 2001, p.124).

Isto posto, o presente estudo recorreu a epistemologia genética para fundamentar a discussão acerca do processo de alfabetização e letramento na perspectiva interacionista de conhecimento, abordando, então, a interação entre o sujeito (alfabetizando) e o objeto de conhecimento (língua escrita), assim como o mediador desse processo (alfabetizador).

\section{A Construção da Alfabetização na Perspectiva Piagetiana}

O processo de alfabetização nunca foi objeto de estudo de Piaget, porém, a partir de sua teoria é possível introduzir a escrita enquanto objeto de conhecimento e o alfabetizando enquanto sujeito

Educ. e Filos., Uberlândia, v. 22, n. 44, p. 141-158, jul./dez. 2008. 
cognoscente. Abordar a alfabetização sobre as bases da teoria piagetiana é, no mínimo, um desafio; tanto para a teoria, que é colocada à prova, quanto para o alfabetizador, que tenta reinterpretá-la, utilizando-a como sistema assimilador. De acordo com Ferreiro e Teberosky (1986), trabalhar com as idéias do mestre de Genebra em um novo campo é uma "aventura intelectual apaixonante", dadas suas possibilidades de respaldar novas aquisições. Segundo as autoras (1986, p.281):

[...] foi graças a essa teoria que pudemos descobrir um sujeito que reinventa a escrita para fazê-la sua, um processo de construção efetivo e uma originalidade nas concepções que nós, adultos, ignorávamos.

A psicologia genética de Jean Piaget e a psicolinguística contemporânea contribuem para desbancar antigas premissas acerca da alfabetização, segundo as quais: a) o alfabetizador e o método de alfabetização são considerados aspectos centrais; b) a criança começa sua aprendizagem da leitura e da escrita somente quando ingressa na escola; c) a alfabetização é centrada no processo de codificação e decodificação.

Se para Piaget todo conhecimento é sempre assimilação de um dado exterior às estruturas do sujeito, a alfabetização, nessa perspectiva, consiste na aquisição de um esquema de assimilação de códigos gráficos, os quais representam um significante da realidade, uma vez que substituem o real por meio de uma convenção, no caso o código alfabético. Sendo assim, pode-se afirmar que a alfabetização compreende os processos de aprendizagem vinculados à objetos simbólicos, enquanto produtos sociais e culturais.

Isto posto, como ocorre a aquisição desse esquema de assimilação, condicionada por um sistema social de significações? Essa questão remete à natureza complexa da alfabetização, a qual compreende dois aspectos distintos e relacionados: o aspecto figurativo da língua escrita (assimilação figurativa - formas e tipos de letras) e o aspecto operativo (mecanismos de codificação das 
letras para representar palavras, requer competência cognitiva e lingüística).

A criança aprende a ler e escrever analisando os dados que lhe chegam sobre esses conteúdos. Essa análise é caracterizada, a princípio, por uma "leitura" das formas gráficas, as quais ela sabe que significam alguma coisa, porém ainda não compreende seus aspectos convencionais. Somente as práticas sociais de interpretação possibilitam identificar essas formas como objetos simbólicos, carregados de determinados significados. Nesse sentido é importante esclarecer que, ao transpor a teoria piagetiana para a prática pedagógica, é necessário considerar que a presença do objeto de conhecimento per se não garante a assimilação, uma vez que são as situações sociais que colocam as significações. Sobre essa questão, Piaget e Garcia (1982, p.228) explicam:

Na experiência da criança, as situações com as quais se depara são prontamente criadas por seu ambiente social, e as coisas aparecem em contextos que lhes dão significações especiais. Não se assimilam objetos 'puros'. Assimilam-se situações nas quais os objetos desempenham certos papéis e não outros.

A atividade de assimilação envolve a compreensão analítica das formas gráficas e do mecanismo de codificação, não ocorrendo respaldada somente no discurso pedagógico do professor, embasado em premissas de um adulto alfabetizado. Para alcançar essa compreensão analítica faz-se necessário uma atividade estruturante da criança, referenciada na interação com o objeto de conhecimento. Daí a importância de acesso à diferentes portadores de escrita, os quais favorecem os esforços de compreensão através de comparação, ordenação e reprodução das marcas que compõem o sistema de escrita. Dito de outra forma, a criança atribuirá significado ao mundo da escrita mediante suas tentativas de assimilá-lo, e é somente em função dessa interpretação que sua conduta deve ser compreendida.

O processo de alfabetização, na perspectiva psicogenética, parte da utilização de significantes (índices, sinais, símbolos), seguida do texto e da apresentação de palavras, colocadas em um

Educ. e Filos., Uberlândia, v. 22, n. 44, p. 141-158, jul./dez. 2008. 
determinado contexto que amplia o seu significado. As palavras são retiradas do mundo real da criança. A atividade de leitura tem início com o processo operacional de análise -síntese, quando a criança "monta e desmonta" a palavra escrita. Sendo assim, o ponto de partida para a alfabetização não são as letras e sílabas.

Uma proposta metodológica que enfatiza somente o aspecto figurativo é respaldada na memorização mecânica de letras, sons e sílabas; seus resultados são superficiais, uma vez que não criam uma situação favorável à compreensão do processo de codificação. O alfabetizando pode obter êxito em repetir os códigos linguísticos, porém enfrentará dificuldades em suas tentativas de leitura e escrita, visto não compreender o sistema de funcionamento do código alfabético: será um mero reprodutor de signos estranhos. Em decorrência, é possível observar um equívoco teórico vinculado à alfabetização: considerar que a aquisição da língua escrita em toda sua complexidade consiste em uma técnica de codificação e decodificação.

A transposição das idéias de Piaget para o campo pedagógico e psicopedagógico não pode desconsiderar os pressupostos psicogenéticos. Pesquisas com crianças de diferentes partes do mundo (Ferreiro e Teberosky, 1986) revelam que a aquisição da língua escrita segue uma trajetória de concepções sucessivas e construtivas $^{2}$. As experiências cotidianas com o objeto de conhecimento, nesse caso a língua escrita, resultam em variações na idade de aparecimento das concepções, mas há uma regularidade que caracteriza, de forma não aleatória, essa trajetória. Isso não significa que a aquisição da língua escrita segue, mecanicamente, uma sequência de fases uma vez que as diferenças individuais não podem ser descartadas.

As conceitualizações sobre a escrita evoluem, principalmente, a partir da diferenciação icônica, ou seja, a criança descobre que para ler e escrever são necessárias determinadas marcas, distintas do desenho (fase pré - silábica). É possível que, a princípio, mesmo

2 Ferreiro e Teberosky (1986) identificaram os seguintes níveis de evolução da língua escrita: pré - silábico; silábico; silábico alfabético e alfabético. 
tendo consciência dessa distinção, a criança não consiga realizar uma leitura desvinculada da imagem, mas ela já tem clareza de que aquelas marcas no papel representam algo. Em suas primeiras tentativas de escrita ou grafismos primitivos, utiliza garatujas ou pseudoletras. Na maioria dos casos, esse conhecimento antecede o ingresso à escola, uma vez que a criança em geral está inserida em um mundo letrado, vivenciando representações e signos diversos.

Após diferenciar o desenho da escrita, a criança compreende que essa é representada por formas arbitrárias, dispostas linearmente (ordenadas em uma seqüência no plano horizontal) e que há dois tipos de signos gráficos: as letras e os números. Seguindo a trajetória de aquisição desse objeto, ela começa a elaborar tentativas de interpretação. Para tanto utiliza de alguns critérios para decidir sobre a quantidade de letras necessárias á escrita. À princípio pode utilizar a quantidade de letras suficiente para preencher a largura do papel, ou usar uma grafia para cada palavra; ou ainda, considerar que o número ou tamanho das letras deve corresponder ao objeto que representam (realismo nominal). Assim, para escrever elefante são necessárias várias letras ou letras grandes; já para escrever formiga são necessárias poucas letras ou letras pequenas. As crianças seguem diferenciando seus critérios, o que pode levar à hipótese quantitativa e qualitativa (Ferreiro e Teberosky, 1986). A primeira refere-se a quantidade mínima necessária para que algo seja escrito, geralmente em torno de três caracteres. A segunda refere-se à variação dos caracteres, ou seja, deve haver uma combinação de posição e formas de letras para que algo seja escrito. Dessa forma, atendendo à natureza desses critérios, a escrita é produzida com no mínimo três letras (caracteres), as quais devem ser diferentes. No caso de outra produção com essas letras, faz-se necessário mudar a posição das mesmas. "Para significados diferentes devem corresponder seqüências diferentes, porém as diferenças que se marcam são fundamentalmente semânticas e não diferenças sonoras" (Ferreiro, 1993, p.85).

Em suas tentativas de reconstrução da escrita, a criança utiliza de todas as informações disponíveis, inclusive do fato de ser falante

Educ. e Filos., Uberlândia, v. 22, n. 44, p. 141-158, jul./dez. 2008.

150 
da língua. Nessa fase, ela não compreende que não há uma correspondência perfeita entre a língua oral e a língua escrita, e levará algum tempo para descobrir que a escrita não significa uma transcrição da fala. Conforme afirma Hagége, “Uma língua escrita não é uma língua oral transcrita: é um novo fenômeno linguístico e cultural." (apud, Ferreiro, 2001, p. 82).

A fonetização da escrita tem início mediante a busca de relação entre a produção escrita e a produção oral (fase silábica: cada sílaba da palavra é representada por uma letra ou uma grafia) ${ }^{3}$. Essa fase é caracterizada pela hipótese de que para escrever algo que apresenta semelhança aos sons da fala, deve haver semelhança de letras na escrita, sendo que as diferenças sonoras devem ser marcadas por produções gráficas distintas. Assim é possível escrever qualquer palavra. É importante assinalar que essa hipótese não corresponde a tentativas de escrita ortográfica, mas sim alfabética. Não se trata de uma hipótese a ser ensinada, ela surge da necessidade interna de coordenar o valor do todo e das partes. É um salto qualitativo a superação da correspondência global entre a forma escrita e a expressão oral para a correspondência entre as partes do todo.

Nessa trajetória, a criança reconstrói seus conhecimentos da língua oral, utilizando-os na produção escrita; em outras palavras, trata-se de reestruturar o que já se sabe para incorporar o novo. Por exemplo, a noção de palavra em nível oral não garante a produção escrita. Faz-se necessário, portanto, uma reelaboração em função das particularidades impostas pela língua escrita. Ou, ainda, nas palavras de Ferreiro (1993, p.101):

Nem o conhecimento do recorte silábico em nível oral basta para desenvolver imediatamente uma hipótese silábica, nem a noção de palavra basta para encontrar as segmentações na escrita, nem a competência dialógica oral basta para responder a uma carta.

3 Em alguns casos excepcionais a escrita silábica pode ser representada por pseudoletras. 
Para progredir e superar essa fase, as mediações externas são fundamentais, uma vez que, devidamente adequadas, desencadeiam conflitos, cuja solução resulta em um nível qualitativamente distinto. É de acordo com seu ritmo e experiências no mundo letrado que a criança verifica que a escrita do tipo silábica não corresponde à escrita convencional ou à escrita utilizada pelo adulto. Essa constatação infantil marca um avanço conceitual, pois coloca a necessidade de rever as hipóteses, buscando uma solução para o problema. Trata-se do conflito cognitivo, tão necessário para o progresso conceitual, como afirma Piaget (1974).

Mediante resultados de pesquisa, Curto (2000) aponta como problema da escrita silábica para a criança: a escrita de palavras monossílabas (como é possível escrever uma palavra com uma grafia quando se está convencido de que é necessário mais de uma letra para escrever uma palavras?); as palavras com letras iguais (se de acordo com a hipótese silábica é correto escrever BATATA, grafando AAA, como é possível ler se todas as letras são iguais?); as palavras diferentes escritas da mesma maneira (não é possível grafar UO tanto para suco como para tubo); os nomes próprios (por que os nomes próprios não se ajustam à hipótese silábica?). Sendo o sistema de escrita do tipo alfabético, o meio proporciona referências que não são interpretáveis pela hipótese silábica da criança.

É na busca de solução para esses conflitos que a criança avança para hipótese silábica - alfabética, caracterizada pela progressiva compreensão do significado de sílaba: uma grafia composta por mais de uma letra. Durante essa fase, a criança combina o critério silábico com escritas parcialmente alfabéticas ${ }^{4}$. A escrita alfabética, por sua vez, é efetivada quando as letras são grafadas de forma convencional. Escrever alfabeticamente não significa escrever ortograficamente; portanto, os conflitos de ordem ortográfica permanecem e serão resolvidos mediante a familiaridade com o sistema alfabético de representação da escrita.

4 A falta de compreensão dessa característica do nível silábico-alfabético, quando a criança escreve Pto para PATO ou CSA para CASA, pode levar o alfabetizador a pensar que a criança está omitindo letras u ainda a classificá-la como disléxica.

Educ. e Filos., Uberlândia, v. 22, n. 44, p. 141-158, jul./dez. 2008.

152 
As experiências cotidianas possibilitam à criança explorar algumas propriedades da língua e formular hipóteses sobre o seu funcionamento. Contudo, para compreensão das reais propriedades que definem esse objeto simbólico e lhe proporcionam valor social é preciso a mediação de um parceiro alfabetizado, o qual utiliza da escrita como significante em seu sentido pleno, ou seja, domina a escrita para resolver questões práticas, ter acesso à informação, interagir com o mundo utilizando formas superiores de pensamento.

A língua é um objeto conceitual. A criança só adquire conceitos se os tiver anteriormente construído. Apropriação de conhecimento significa um processo ativo de reconstrução, uma compreensão do modo de produção. Assim, a natureza do conhecimento é assimiladora e não registradora (acúmulo de informações). Dessa forma, para conhecer faz-se necessário processar, operar com a informação. Se a compreensão carece de esquemas de assimilação originados na ação sobre o objeto de conhecimento, o mediador precisa planejar adequadamente as situações, entendendo que propor condições de aquisição não corresponde a ensinar formalmente, mesmo porque, do ponto de vista da psicogênese, as aquisições se realizam por caminhos que não são determinados pela escola. As pesquisas de Ferreiro e Teberosky (1986) evidenciam que, independente da metodologia de trabalho do alfabetizador, as crianças não avançam no mesmo ritmo, sempre há níveis distintos de conceitualização. Isso ocorre porque o método não cria aprendizagens, o conhecimento é resultado da própria atividade do sujeito: a ação desencadeia todo processo de conhecimento.

No decorrer do processo de alfabetização, a intervenção do mediador deve ocorrer no sentido de favorecer a compreensão dos modos de representação da linguagem, uma vez que para se ingressar no mundo letrado a criança precisa resolver os problemas conceituais vinculados à compreensão do sistema alfabético de escrita. Ela não se alfabetiza com base apenas em suas hipóteses sobre o processo de leitura e escrita, de modo que é fundamental a transmissão de conhecimentos. Isso significa que negar a mediação do professor no processo de ensino é um grande equívoco educacional. 
A própria postura do professor enquanto usuário da língua é um referencial importante, ele ensina também ao servir de modelo no uso da linguagem escrita, portanto seus encaminhamentos de leitura, sua forma de utilizar o código, independente de situações específicas de ensino, servem de referencial para o aluno, por exemplo: lê em sala algum comunicado da direção da escola ou um bilhete encaminhado por um pai de aluno, uma notícia de jornal, uma carta, etc.

Faz-se necessário, também, trabalhar a função social da escrita, cuja importância extrapola os limites da escola; a leitura compreensiva de diferentes registros e materiais portadores de escrita (jornais, livros, revistas, cartas, bilhetes, receitas, outros); a produção de textos coerentes e coesos, com diferentes propósitos. Essa trajetória é marcada por organizações, desestruturações e reestruturações constantes, haja vista que a criança sistematiza e põe à prova a organização obtida durante suas tentativas de compreensão do objeto.

As tentativas de compreensão da linguagem ficam prejudicadas mediante o uso de materiais de alfabetização definidos a priori. Esses recursos são frequentemente contraproducentes, pois desconsideram uma capacidade vital da criança: a capacidade de pensar. E por que pensar é importante? Porque pensar significa criar, construir e reconstruir, problematizar incessantemente, buscar sem parar. Essas características são fundamentais para efetivação de uma aprendizagem significativa, contrária à conotação empirista que este termo pode adquirir.

Por outro lado, o uso de materiais padronizados pode retirar a oportunidade de situações mais interessantes, como por exemplo: vivenciar atos de leitura e de escrita, explorar semelhanças e diferenças entre textos escritos, emitir opiniões sobre textos, fazer perguntas e oferecer respostas conforme as hipóteses disponíveis, tentar produzir um texto, explorar os diferentes portadores de texto existentes no ambiente. Em suma, a escrita, enquanto objeto de conhecimento, deve estar presente de forma plena e não ser dosada através de propostas metodológicas fixas e/ou padronizadas. Quando se adota esse procedimento de trabalho, incorre-se no

Educ. e Filos., Uberlândia, v. 22, n. 44, p. 141-158, jul./dez. 2008.

\section{4}


equívoco de deixar o material conduzir o ensino e a aprendizagem em prejuízo da interação entre o aluno e o professor. Os alfabetizadores não podem delegar a responsabilidade da mediação na aprendizagem, o que implica revisar algumas idéias subjacentes à tarefa de ensinar. Segundo Curto (2000, p.68):

Ensinar não é apenas transmitir informações a um ouvinte. É ajudálo a transformar suas idéias. Para isso, é preciso conhecê-lo, escutálo atentamente, compreender seu ponto de vista e escolher a ajuda certa de que necessita para avançar: nem mais nem menos.

Para alfabetizar com base nos pressupostos piagetianos, o professor precisa dispor-se a entender o pensamento infantil sobre a língua escrita, analisar as produções como passos construtivos de um processo e não como resultado definitivo, precisa aceitar que as crianças têm hipóteses complexas e compreensivas sobre o sistema alfabético de representação, construídas em suas tentativas de compreensão da natureza da linguagem. Para tanto, deve oferecer oportunidades para que a criança pense, exponha sua lógica, revele suas dúvidas, faça seus questionamentos.

Por fim, trata-se de considerar a alfabetização não apenas como aquisição de um código linguístico, mas enquanto uma estrutura sobre a qual outros conhecimentos serão construídos. Assim tornase possível alcançar o objetivo principal da educação na perspectiva de Piaget: desenvolver a capacidade humana de criar e não simplesmente repetir o que a humanidade já sabe.

\section{Considerações Finais}

A realidade do mundo globalizado impõe novas perspectivas ao processo de alfabetização: não basta dominar os mecanismos de codificação e decodificação, é necessário ir além desse saber para construir conhecimentos e engajar-se socialmente. Em outras palavras, aprender a ler e escrever não pressupõe somente compreender um conjunto de regras e normas, mas também adquirir competência comunicativa para utilização adequada da língua em qualquer circunstância.

Educ. e Filos., Uberlândia, v. 22, n. 44, p. 141-158, jul./dez. 2008 
De acordo com essa tendência ampliam-se as funções dos professores alfabetizadores, que devem atribuir novos sentidos e significados aos usos funcionais da língua. Isso quer dizer (re) definir os conceitos teóricos e metodológicos que embasam os procedimentos didáticos - pedagógicos. Para tanto, precisa haver disposição para rever posturas e concepções acerca dos alunos, dos processos de ensino e de aprendizagem e, também, de alfabetização.

Ao abolir a visão reducionista do ato de ler e escrever, o professor passa a valorizar o meio sócio-cultural em que as crianças estão inseridas, contextualizando o ensino da língua, uma vez que os conhecimentos são construídos ao serem trabalhados em contextos sociais e situações comunicativas diversas. Ao buscar referência nas práticas sociais de leitura e escrita, o ensino transforma a relação das pessoas com o conhecimento. Esse processo é gradativo, envolve erros e acertos, daí a necessidade de mediação teórica, de momentos de estudo e reflexão.

Nesse sentido alguns princípios piagetianos podem ser pertinentes para uma intervenção na alfabetização. Com base nessa matriz explicativa a compreensão de determinado objeto de conhecimento, neste caso a língua escrita, está estreitamente relacionada às possibilidades do sujeito reconstruir esse objeto, a partir da compreensão de suas leis de funcionamento, o que equivale a reconstrução da língua pelo entendimento de seus elementos constitutivos. Para tanto é preciso criar situações de intervenção, por meio das quais ocorre a mediação pertinente ao processo de aprendizagem. Essa dinâmica interativa é contrária ao planejamento massificante, isto é, o plano único de atividades para todos os alunos. A partir da consideração das diferentes concepções que os alfabetizandos podem apresentar em relação a língua escrita, torna-se inviável propor o mesmo trabalho a todos. $\mathrm{O}$ alfabetizador que desconsidera essa realidade e massifica seus alunos com uma proposta única, atende a uma parcela da turma, geralmente aqueles que já construíram vários dos conceitos sobre a linguagem, enquanto os demais ficam à margem do processo e são os candidatos ao fracasso escolar. Para estes a escola deixa

Educ. e Filos., Uberlândia, v. 22, n. 44, p. 141-158, jul./dez. 2008.

156 
muitas lacunas no cumprimento de sua função social de produção e socialização do conhecimento, e ainda, discrimina e classifica os que podem e os que não podem aprender. Por meio de seus "mecanismos legais" de avaliação, faz com os alunos assumam a responsabilidade de seu "fracasso", com todas as implicações sociais decorrentes desse fato.

Não é essa a educação que a maioria dos brasileiros almeja e necessita. Se o acesso aos patamares mais elevados do conhecimento é direito inalienável de todos os cidadãos, cabe a escola assegurar as condições favoráveis ao desenvolvimento pleno das potencialidades de seus educandos. Isto significa educar na perspectiva da diversidade, construindo uma cultura de integração em detrimento da reprodução de modelos pedagógicos prédefinidos e alienantes.

\section{Referências}

COTES, Paloma. Fábrica de analfabetos - Pesquisa inédita mostra que $96 \%$ das crianças da escola pública saem da $1^{\text {a }}$ série sem ler e escrever. Revista Época, Rio de Janeiro: Editora Globo, edição 267, 2003.

CURTO, L.M. e al. Escrever e Ler - Como as crianças aprendem e como o professor pode ensiná-las a escrever e a ler. Vol. I. Porto Alegre: ARTMED, 2000.

FERREIRO, Emília. Com Todas as Letras. $2^{\mathrm{a}}$ ed. São Paulo: Cortez, 1993.

Atualidade de Jean Piaget. Porto Alegre: Artmed, 2001.

FERREIRO, Emília. \& TEBEROSKY, Ana. Psicogênese da língua escrita. Porto Alegre: Artes Médicas, 1986.

FREIRE, Paulo. Extensão ou comunicação. Rio de Janeiro: Paz e Terra, 1977. 
. Educação e Mudança. Rio de Janeiro: Paz e Terra, 1979.

Jornal "O Popular". Índice de analfabetismo funcional é preocupante. Goiânia: Agência Estado, 2000.

KLEIMAN, Ângela B. Os significados do letramento: uma nova perspectiva sobre a prática social da escrita. Campinas: Mercado das Letras, 1995.

MIRANDA, Maria Irene. Crianças com Problemas de Aprendizagem na Alfabetização: contribuições da teoria piagetiana. $2^{\mathrm{a}}$ ed. Araraquara: JM Editora, 2003.

- Projeto de Intervenção Escolar para Alunos com Problemas de Aprendizagem na Alfabetização: construção, implementação e resultados. Tese de Doutorado. Pontifícia Universidade Católica de São Paulo. São Paulo, 2005.

PIAGET, J. O Nascimento da Inteligência da Criança. Trad.: Trad. Álvaro Cabral. Rio de Janeiro: Zahar Editores, 1974.

Para onde vai a educação. Rio de Janeiro: J. Olympio, 1975.

PIAGET, J. e GARCIA, R. Psicogénesis e Historia de la ciencia. México: Siglo XXI, 1982.

ROJO, Roxane (org.). Alfabetização e letramento. Campinas: Mercado das Letras, 1998.

SOARES, Magda. Letramento - Um tema em três gêneros. Belo Horizonte: Autêntica, 1998. 